\title{
Optimization of building design process by using energy simulation tools
}

\author{
Piotr Ziembicki* \\ University of Zielona Góra, Faculty of Civil Engineering, Architecture and Environmental \\ Engineering, Prof. Z. Szafrana 15 str., 65-516 Zielona Góra, Poland
}

\begin{abstract}
Requirements concerning energy efficiency of buildings, as well as the emission of energy sources working for their needs, are constantly growing. It is related to the Polish law, as well as European Union directives. It is obvious that in the coming years, further regulations and directives will impose additional requirements in this area. Therefore, the requirements for the operation of buildings and process of their designing are changing already today. In the past, the design process, in particular in the aspect of energy consumption, was based primarily on the procedures of static analysis of the building's structure (partitions, glazing, etc.). A typical calculation of a building heat demand did not take into account other aspects of the building's operation, such as user behaviour, heat gains or thermal accumulation of the building. Therefore, in modern designing, it is extremely important to use advanced computer techniques to develop a detailed balance of energy, which takes into account all its useful forms, including heat and electricity. Only such a comprehensive approach will render it possible to achieve the energy efficiency indicators required by law, as well as an economically efficient operation of the building, with a minimal bad influence on the environment. In general, the manuscript presents methods of comprehensive computer energy simulation of buildings, which can be used for optimal designing of buildings for any purpose. The article also presents an overview of available computer tools, which are recommended for the building design process. There are also some examples of using a simulation software for the analysis of residential buildings, along with the analysis of the results of energy simulations carried out with its help.
\end{abstract}

\section{Introduction}

The development of science and technology as well as social and economic progress require offering solutions to more and more complicated technical problems. Each of such solutions calls for an understanding of a process or system under investigation. In many cases, however, the level of knowledge available does not allow an explicit or unambiguous determination or solution to such problems. Frequently, it is not possible to develop exact calculation methods either. The same applies to energy performance of buildings, heat

\footnotetext{
* Corresponding author: p.ziembicki@iiis.uz.zgora.pl
} 
sources and heating as well as cooling installations, which constitute complicated systems of devices, fittings and control equipment, cooperating with one another, operating in different, frequently unpredictable conditions, and which have to ensure a proper environment for the life and work of their users. In order to design in a proper manner the heating and cooling sources for the needs of air-conditioning of a building it is necessary to work out the balance of heating and cooling demand for the building. In most of the cases, it does not suffice to make calculations using the traditional calculation methods and methods specified in the regulations in force and Polish standards. In order to make it possible to achieve an in-depth analysis of a building it is necessary to know the energy performance of the building which follows from its construction, its profile, i.e., how it is used, and to understand the operation of heating and cooling sources, as well as of the heating and cooling installations.

\section{Computer energy simulations}

Advancements in computer technologies and availability of essentially unlimited computer performance accelerated significantly the development of computer methods of data processing. This fact is of particular importance for various branches of engineering, in which it is necessary to solve, among others, extremely complex balance equations (mathematical models) that for instance apply to the energy performance of buildings or energy sources, and, generally speaking, to the systems that generate and distribute electrical energy and heat. Such issues should be solved by using computer simulations, which can be defined in many various ways. Malinowski in [10] defined simulation as an information experiment made on a model of the system in order to determine the significance of changes in the values of parameters or the values of forecast variables. In $[20,21]$ simulation was defined as a methodology for solving models understood as sets of variables and their relations with the use of dedicated computer software in order to:

- describe and explain the operations of the system,

- forecast the operation of the system in future and under various conditions of environmental impacts,

- choose appropriate input impacts, which satisfy prescribed conditions, particularly to select optimal impacts,

- choose the structure or parameters of the system which would satisfy the prescribed tasks.

It should be emphasized that the degree of detail of the model describing the system is an extremely significant element which affects the quality of modelling and simulation results. The larger the model, the more realistic it is and simulation results resemble the reality. It follows, however, from the engineering practice that a reasonable introduction of limitations in the degree of data detail to the model is both economically and technically justifiable. According to Nelles, system identification taking into account numerous details requires much effort and time while developing a model and this in turn results in higher costs which must be substantiated by the weight of the problem [12]. In addition, once a detailed model is developed, the costs of the necessary software and time required for simulations increase. The costs of testing also rise, the number of data increases as well as the difficulties in manipulating the system's features. It happens frequently that satisfactory results are obtained after the first run of computer simulations and an introduction of further details to the model does not result in their better quality. If such instances are avoided, the time for the development of the model and time of simulations are reduced.

Such an optimal approach to the analysis of systems is particularly substantiated in the case of building energy performance simulations made for the construction and installation branches of industry. Buildings, including their fittings and users (i.e., residents or employees working there) constitute particularly complicated systems, which frequently cannot be 
described in mathematical terms, for instance in terms of the building operation schedule, (i.e., how and when the building is used) or in terms of the impact of activities undertaken by residents or users of the building on its energy performance. It should be underlined that in practice it is not possible to consider the above mentioned parameters in the analysis of building energy performance which employs traditional calculation procedures based on standards and directives, which are not only frequently out-dated, but also in many cases do not satisfy the current requirements. In addition, the above mentioned methods do not make it possible to determine the trends of changes in building energy performance parameters throughout a whole year, e.g., taking into consideration the dynamics of changes in the building heat load depending on the outdoor temperature or making a correct provision for heat accumulation in a building. This affects to a great extent the results of building energy performance analysis and indirectly affects the appropriate choice of both energy sources for a building and its fittings, e.g., heating, ventilation or air-conditioning systems. In this context, the key issue is to change the approach to building energy performance analyses by introducing to the engineering practice, to the greatest possible extent, computer simulations and software that use mathematical models of heat exchange processes, which ensure obtaining correct results even though the features of the building are not frequently described in full.

\subsection{Simulation software and engines}

The problem of energy simulation of buildings, heat sources, heating systems and domestic hot water supply have been studied for more than 40 years. The studies have resulted in the development of a great number of computer programmes and applications of different functionality and level of complexity, from spreadsheets to specialist simulation tools (EnergyPlus, Polysun, TSOL, eQuest, CFD software, etc.), which combine various aspect of building design [5-7,9,13,15-19].

All simulation calculations, considered in the paper, were made with the use of EnergyPlus simulation software, which is intended for carrying out building energy performance analysis. It has an added capability of making a detailed simulation of the heat load and annual energy consumption. By using EnergyPlus, the demand for heating, cooling and electrical energy, which must be supplied to the building in order to maintain the required standards of comfort, can be simulated on the basis of a detailed description of the building, its installations and fittings. Moreover, an analysis of primary energy consumption renders it possible to determine the energy efficiency of the building and this, in consequence, may constitute the basis for drawing conclusions as to the introduction of constructional and functional changes in the building that would reduce energy consumption.

It is worth emphasizing that at present it is the most modern and most advanced calculation tool designed for that purpose. Making a building energy performance simulation in EnergyPlus is not based on elaborating from scratch each time a new mathematical model, but on using verified calculation results for individual elements of the building infrastructure (e.g., a detailed model of heat transfer by Convection „TARP”). Each new version of the engine is tested in accordance with the ANSI/ASHRAE 140-2011 standard and compared with the basic building simulation programmes (ESP-r, BLAST, TRNSYS, etc.) [8]. The individual simulation methods of EnergyPlus calculation engine have been validated successfully many times on the basis of real buildings [3,11,14]. Also, DesignBuilder used in this manuscript as a graphical user interface (GUI) is a tool employed in research studies; works such as $[1,2,4]$ may serve as an example. It should be underlined that EnergyPlus is a software that does not have a graphical user interface. The application comprises only an engine which includes complete calculation (simulation) procedures and defined input and output as simple ASCII text files. This solution enables development of the graphical user 
interface by external companies, thus it allows designers to focus on its intuitive character and functionality and relieves them from programming the computational algorithms (which are programmed by EnergyPlus programmers). Additionally, input and output data defined as simple text files facilitate the exchange of data between the engine and the GUI. This ensures stability of the whole package and improves the reliability of the programme as it allows an analysis of the correctness of the input and output data at each stage of the system operation.

Advanced calculation capabilities of EnergyPlus and its popularity have created interest in developing applications being a graphical user interface, which facilitate data entry and display of simulation results both in a text and graphical form (charts, visualizations of heat flow, etc.) Currently, many applications of this type are being developed, but Design Builder software is one of the most popular and offers most capabilities. The software is dedicated to developing 3D models of buildings with the use of a rich database of predefined building materials, construction of walls and installations. This, in combination with the inheritance of the features by successive elements defining the level of detail of the building description, allow a quick and precise modelling of buildings.

\section{Building heat sources optimization}

Computer simulation of building energy performance can be employed for analyzing buildings of any type in any climatic conditions. The modern software used for the research presented in this article, i.e., EnergyPlus (Design Builder), is extremely flexible and renders it possible to introduce practically any simulation boundary conditions. Such variables include, among others, climatic data (outdoor temperature, solar radiation intensity, winds, relative humidity), construction and structure of the building, division into heating zones of various characteristics, heat gain loads, schedule of building operation, etc. Such features of the software allow, among other things, simulations of the heating load and cooling load of the building for various temperatures and insolation. This is of particular importance due to climate changes which have taken place within the last decades.

In order to analyse the feasibility of optimizing the choice of a heat and/or cooling source for a given building, a simulation of energy performance analysis was carried out for two completely different buildings: a large office building and a small two-family house (a semi-detached house). The buildings under analysis are real buildings, of which one (the office building) has been used for many years and the analysis aimed at suggesting an optimal heat source for the heating needs of the building, whereas the other has been newly designed and has features of a low-energy building, in which it was necessary to design a heat source (or heat sources - separately for each individual part of the building) for the heating needs and domestic hot water supply.

\subsection{Optimization of heat and electricity energy source for the office building}

Within the research and implementation project carried out at the University of Zielona Góra , energy performance analyses were made which aimed at optimizing the choice of heat and electricity energy source for an office building. The building chosen for the simulations comprised two buildings connected with one another (marked "A" and "B"). The total cubic capacity of the buildings was $18150 \mathrm{~m}^{3}$, whereas the net area was $4253 \mathrm{~m}^{2}$. The office building was supplied with heat by the district heating network through a heat exchange station located in the basement part of the building. The building was equipped with a traditional radiator heating system supplied with the heating medium of the parameters: $85 / 65^{\circ} \mathrm{C}$. The building was also equipped with the following systems: a mechanical supply - exhaust ventilation and air-conditioning fitted with compressor units. 
The maximum heat load of the building calculated by independent designers, who used traditional methods of calculation, was $230 \mathrm{~kW}$. While the heat load of the building was calculated by means of traditional methods, no in-depth analysis of building energy performance was made. As a result of this, a newly designed energy source for the building could not have been optimized in any way. Therefore, the main objective of the research and energy performance simulations carried out was to analyse the advisability of making a modern electricity energy and heat source in the building (ultimately also a cooling source for the needs of the air-conditioning system), in the form of a CHP (combined heat and power) unit, which in future was supposed to be extended with a sorption chiller (trigeneration system). To this end, the building simulation model was made with the use of the Design Builder software (based on EnergyPlus calculation engine), which is presented in Figure 1 .

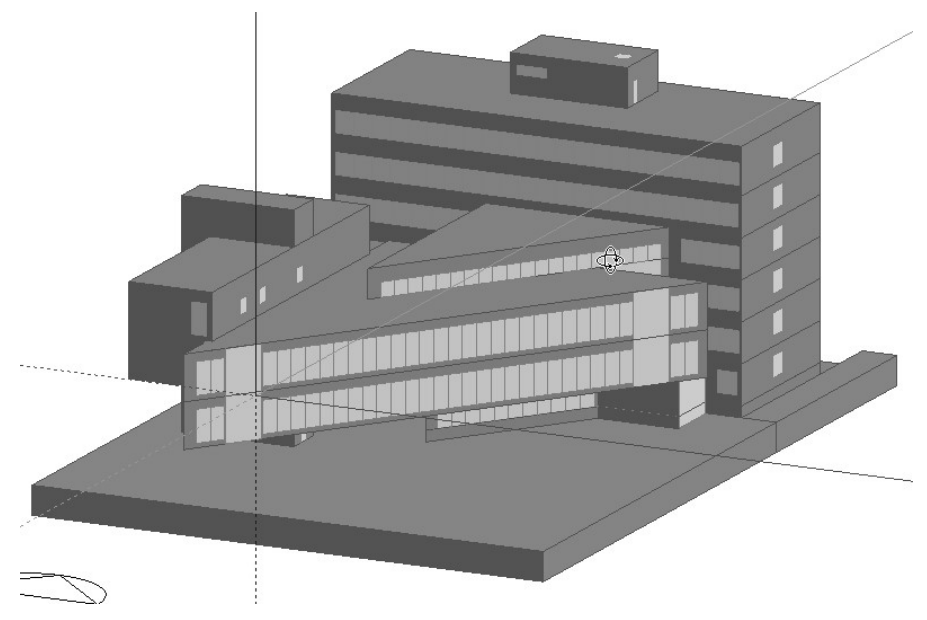

Fig. 1. The 3D model of the office building

The simulation model developed allowed a detailed analysis of the annual changes in the heat load and heat consumption in the building. This in turn rendered it possible to make an optimal choice of the CHP unit. The power of the unit was selected in such a way as to secure its operation on the basis of heat demand. Utilization of useful heat generated by the CHP was on the level of $83 \%$, whereas the contribution of useful heat generated by the CHP unit to the total demand amounted to $75 \%$. Obtaining such high values would not have been possible if the analyses had been based on a traditional heat balance calculation. Figure 2 illustrates the nominal heat power of the CHP unit on the background of the ordered diagram of heat load. It should be stressed that economic efficiency of the solution, especially investment costs, were treated as significant parameters and were taken into particular consideration in the simulation analysis. 


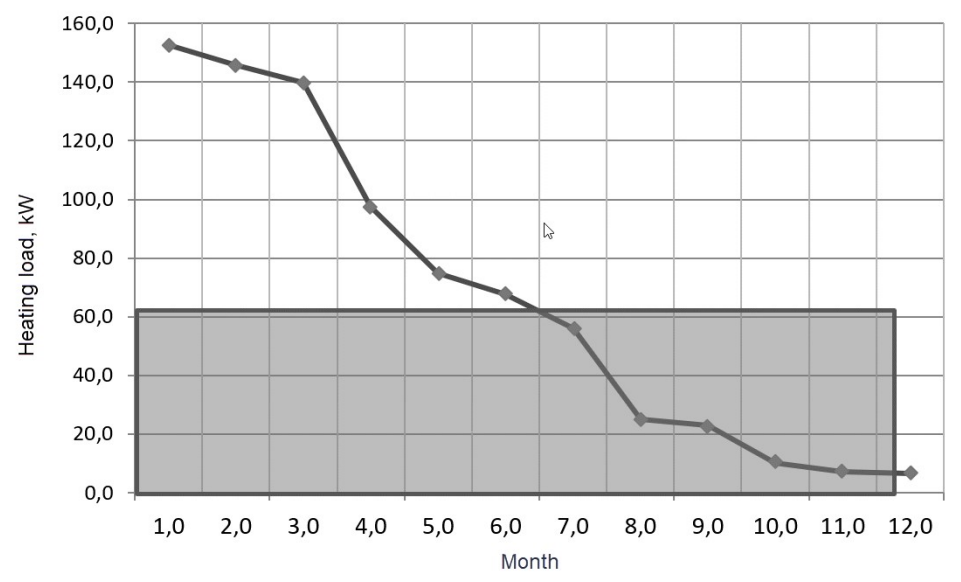

Fig. 2. The nominal heat power of the CHP unit on the background of the ordered diagram of heat load

A very important aspect of the source selected was the generation of electrical energy in combination with the generation of heat for the heating needs. The optimal choice of the CHP unit ensured its operation for 8500 hours annually, at full power. This in turn secured generation of electrical energy at a level satisfying the needs of the building, irrespective of its operation schedule. The demand for electrical energy for the server room in the building, emergency light and other systems working round-the clock was fully covered by the electrical energy generated with very high efficiency by the CHP unit. In the first four months of its operation, a total net profit of approximately $22500 \mathrm{PLN}$ was generated. Savings in the costs of operation and profits gained due to the optimal selection of heat and electricity energy sources proved to be so encouraging that the Company Board decided to expand the technological system with an absorption chiller which was to produce ice water for the needs of the air-conditioning system operating in the whole building.

It should be emphasized that it would not have been possible to obtain so significant profits from the operation of the optimally selected CHP unit, unless a computer simulation of the building energy performance had been made at the preliminary stage of the research. The simulation yielded complete and detailed information on the changes in the heating, cooling and electrical load on the building for the period of the whole year with the time step of 30 minutes.

\subsection{Two-family residential building}

Computer simulation of building energy performance is an extremely flexible tool and it can be used for the analysis of both office buildings, multi-family residential buildings, or smaller ones, single or two-family residences. In all these cases, the application of these simulation algorithms allows optimization of the design process and the results achieved lead both to increasing the energy performance efficiency of the architectural and constructional as well as installation solutions proposed and to reducing investment and operational costs.

A simulation model of a two-family building (semi-detached type) was developed as a result of the research and implementation project and analyses carried out at the University of Zielona Góra. The model was made on the basis of the construction documentation made available, site inspection, and arrangements made with the persons supervising the investment project. Drawings of the ground floor and attic layout plan, cross-sections and also views of the façade were used (Figure 3). Moreover, the investor submitted simplified designs of the central heating, electrical and water and sewer installations. 


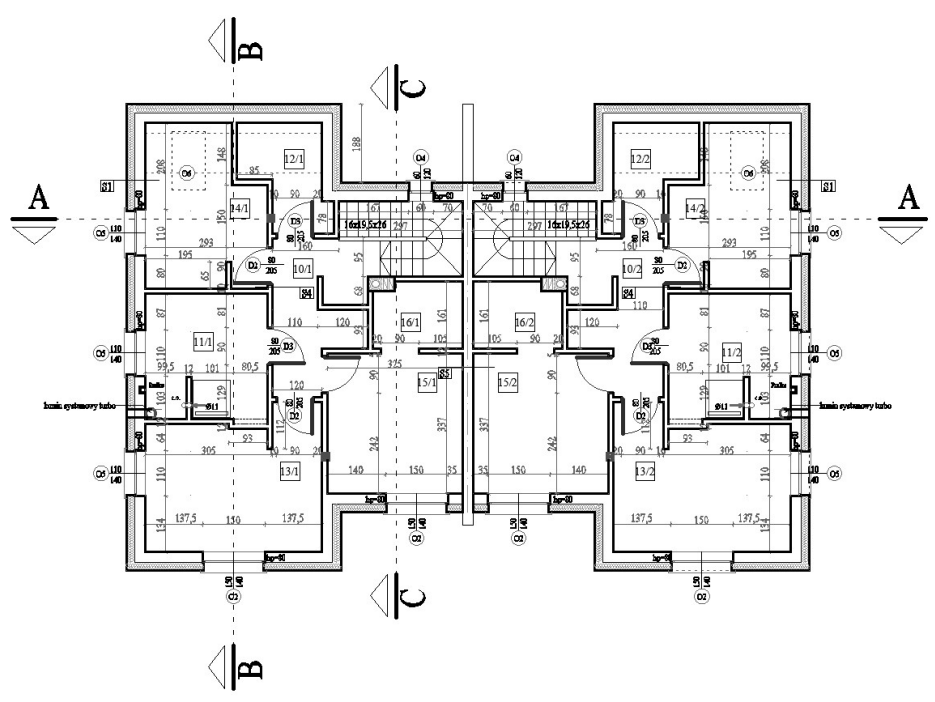

Fig. 3. A scheme of the attic in the two-family house

Similarly as in the case of the office building, the simulation model of the two-family house was made in Design Builder (based on EnergyPlus calculation engine). The construction and the overall dimensions of the building were reproduced on the basis of the construction documentation employing the mechanisms of the software which made it possible to develop a three dimensional model of the building (Figure 4). The model reflected precisely the real building. Its fittings and characteristics of operation were broadly parameterized. It made it possible to prepare various variants of simulation calculations and, in consequence, allowed an optimization of the heat source solutions which were proposed.

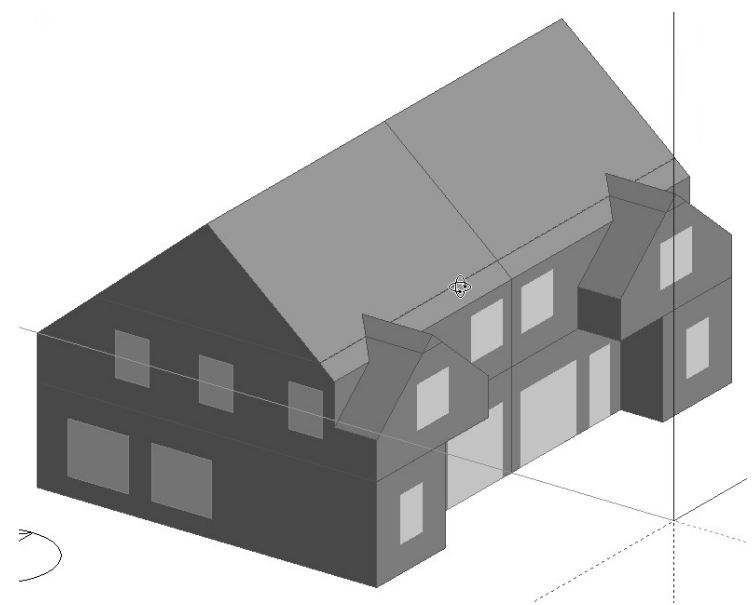

Fig. 4. The 3D model of the two-family building

In order to make the building energy performance simulation in Design Builder it was required to divide the building into zones constituting sectioned off areas, for which separate parameters of indoor air and building installations, heating and cooling facilities are defined. Irrespective of the division of the building into calculation zones, general assumptions were adopted relating to the whole building connected with equipping the building with 
installations and the manner of its operation. The assumptions referred to, among others, tightness of the building, stabilized indoor temperature, frequency of air exchange, etc., were adopted in accordance with the regulations and standards in force.

The results of the simulation analyses are presented in the form of graphs illustrating changes in the annual demand for energy to meet the heating and cooling needs in the building. Figure 5 presents changes in the outdoor temperature and heating and cooling load for the whole building. In order to make a thorough analysis of the building, separate energy performance simulations were also performed for both parts of the building, and also for each room individually.

The design parameters of the energy source for the whole building (for the climate data for Zielona Góra considered in the simulation calculations) were as follows:

- annual heat demand - $18037,1 \mathrm{kWh} /$ p.a.,

- annual cooling demand $-717,1 \mathrm{kWh} /$ p.a.,

- maximum cooling power $-4,9 \mathrm{~kW}$,

- maximum heating power $-10,8 \mathrm{~kW}$.

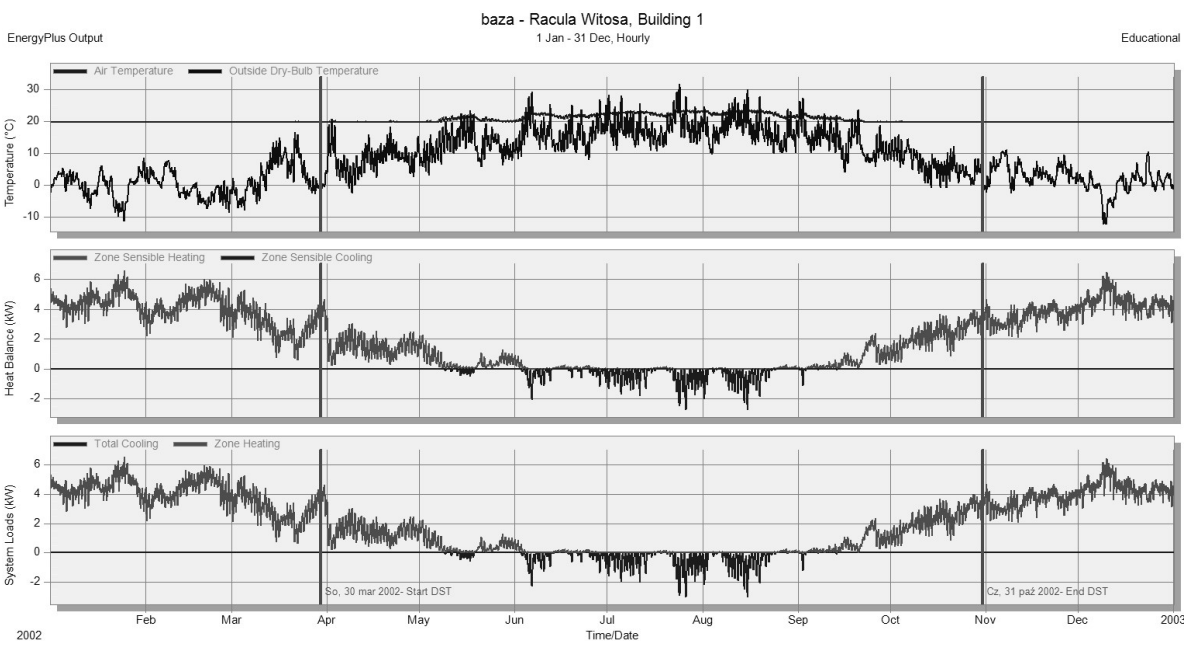

Fig. 5. The results of the whole building energy performance

The design parameters of the energy source for the single part of the building (for the climate data for Zielona Góra considered in the simulation calculations) were as follows:

- annual heat demand - $9018,6 \mathrm{kWh} / \mathrm{p} . \mathrm{a}$.,

- annual cooling demand $-358,6 \mathrm{kWh} / \mathrm{p} . \mathrm{a}$.,

- maximum cooling power $-2,5 \mathrm{~kW}$,

- maximum heating power $-5,4 \mathrm{~kW}$

Attention should be drawn to the fact that in the chart illustrating changes in the heat load for the whole building we can see that the value of this parameter exceeds altogether only 6 $\mathrm{kW}$ for 24 hours within several days in December and January (the maximum value of heat load: 6,6 kW). The maximum cooling power for the whole building follows a similar pattern - the highest value is $3,1 \mathrm{~kW}$.

The results obtained were compared with the design parameters for the building heat source determined by means of traditional calculation methods (static balance of the building heat load and cooling load). The maximum heating power of the heat source for the single part of the building calculated and presented in the documentation was $14 \mathrm{~kW}$. This means that this value was over-designed almost 2,5 times $(5,4 \mathrm{~kW}$ calculated by means of computer 
simulations). If such a heat load balance had been accepted, it would have resulted in a completely non-optimal choice of the energy source and would have increased investment costs as well as operating costs. The energy performance computer simulation which was performed made it possible to recommend an installation of a single heat source (additionally equipped with separate metering systems) for both parts of the building. The optimization carried out with the use of computer simulations allowed saving at the stage of investment implementation almost $2 / 3$ of the forecast budget allocated for building the heat source for the two-family building. In addition, the properly selected heat source will work with significantly higher efficiency than it was originally provided for in the construction design, because it will be optimally loaded.

\section{Conclusions}

Increased requirements regarding building energy performance compel engineers to develop more and more precise architectural, constructional and installation designs. The requirements pertaining to low or zero-emission buildings in practice make it impossible to use traditional, typical calculation methods based on static energy balances defined in standards, guidelines and directives which were frequently worked out a dozen or several dozen years ago. It is absolutely indispensable to employ modern analytical methods based on high-class calculation algorithms implemented in advanced computer software. The examples of simulation models of buildings and energy sources presented in this paper allowed a considerable reduction of investment costs and at the same time increased the energy performance effectiveness. This shows that a broad implementation of computer simulation methods in the areas of construction and installation engineering is vital and of crucial importance. However, on account of the fact that it will be necessary for designers to acquire new skills and due to high costs of the simulation software, the process of implementing the new methodology will be complex and time-consuming.

\section{References}

1. G. Allesina, E. Mussatti, F. Ferrari, A. Muscio, Energ Buildings 158 (Supplement C), $406-416,(2018)$

2. R. Andarini, Energy Proced 47 (Supplement C), 217-226, conference and Exhibition Indonesia Renewable Energy \& Energy Conservation [Indonesia EBTKECONEX 2013], (2014)

3. A. S. Andelković, I. Mujan, S. Dakić, Energ Buildings 118 (Supplement C), 27-36, (2016)

4. E. L. Cascio, Z. Ma, D. Borelli, C. Schenone, Energy Proced 111 (Supplement C, 91100, 8th International Conference on Sustainability in Energy and Buildings, SEB-16, 11-13 September 2016, Turin, Italy, ) (2017)

5. D. B. Crawley, J. W. Hand, M. Kummert, B. T. Griffith, Build Environ 43 (4), 661-673, part Special: Building Performance Simulation, (2008)

6. N. Fumo, Renew Sust Energ Rev 31, 53-60, (2014)

7. V. Harish, A. Kumar, Renew Sust Energ Rev 56, 1272-1292, (2016)

8. R. H. Henninger, M. J. Witte, ASHRAE standard 140 2011, (2013)

9. M.-T. Ke, C.-H. Yeh, J.-T. Jian, Energ Buildings 61 (Supplement C), 100 - 107, (2013)

10. P. Malinowski, Modelowanie hydrodynamiczne i optymalizacja systemów zaopatrzenia w ciepło, Politechnika Wrocławska, (2009) 
11. N. M. Mateus, A. Pinto, G. C. da Graca, Energ Buildings 75 (Supplement C), 511-522, (2014)

12. O. Nelles, Nonlinear system identification. From classical approaches to neural networks and fuzzy models, Springer, (2001)

13. J. New, W. A. Miller, Y. J. Huang, R. Levinson, Energ Buildings 114, 130-135, (2016)

14. W. Pereira, A. Bogl, T. Natschlager, Energy Proced 62 (Supplement C), 472-481, (2014)

15. S. Pourarian, A. Kearsley, J. Wen, A. Pertzborn, Energ Buildings 122 (Supplement C), 53-62, (2016)

16. A. Staszczuk, T. Kuczyński, M. Wojciech, P. Ziembicki, Comparative calculation of heat exchange with the ground in residential building including periodes of heat waves, Civil and Environmental Engineering Reports 21 (2), 109-119, (2016).

17. Z. Tian, W. Chen, P. Tang, J. Wang, X. Shi, Energy Proced 78 (Supplement C) $2572-$ 2577, 6th International Building Physics Conference, (2015)

18. M. Trcka, J. L. Hensen, Automat Constr 19 (2), 93-99, (2010)

19. T. Yamamotoa, A. Ozakia, M. Leeb, H. Kusumotoa, Energ Buildings 159, 587-599, (2018)

20. P. Ziembicki, J. Kozioł, B. Mendecka, Innowacyjne metody zarzadzania $w$ energetyce komunalnej, University of Zielona Góra, (2018)

21. P. Ziembicki (red.), Rozproszone kogeneracyjne źródta energii dla budynków, University of Zielona Góra, (2013) 